\title{
Health care and hospital management in India
}

\author{
Shaikh Mahmood \\ Lab Manager, Dept. of Physiology, Deccan College of Medical Sciences, Hyderabad, Telangana, India \\ *Corresponding Author: Shaikh Mahmood \\ Email: mahmood_shaikh2001@yahoo.co.in
}

\begin{abstract}
Public health care has been of national and international related as in the methods of witnessing the health care standard of any nation in the world. It mobilises and engages nationally and internationally. Since the health care concern problems and issues vary from country to country. Good health is a pre- requisites for human productivity and development process. It is important and essential for socio economic and scientific development. Health and health care is a common phenomenon in most of the cultures and communities. Health and health care is the absence of any disease. The objective of this research is the study of the development of health sector in India. The study will evolve the concept of globalisation, development of information technology (Telemedicine) medical tourism, role of urbanization growth of health care insurance sector, affordability of health care in India. The role played by major privet health care firms in India.
\end{abstract}

Keywords: Health, Health care, Hospital management, Telemedicine, Urbanization, Globalization.

\section{Methods and Materials}

The data collected in this study is from different health care survey in India, heath care websites, journals, newspapers, health magazines and conferences.

\section{Results}

Rising demand of health care in India is one among the leading developing Countries in health care. The major factors in this study are include increasing growth population, growing lifestyle related health issues, cheaper costs for treatment, thrust in medical tourism, improving health insurance penetration, increasing disposable income, government initiatives and focus on public - private partnership models.

\section{Conclusion}

With rising health care and hospital management (telemedicine) demand in India, government, private sectors and health care organisations are to come with the concept of digitalisation development of future endeavours.

\section{Source of Funding}

None.

\section{Conflict of Interest}

None.

\section{References}

1. Globalization and its importance in India, economy, development and challenges.008-11, January, 2019.

2. Business standards, victories of countries. 005-11, July, 2019.

3. Chennai city gets most foreign trades. 412-416, September, 2019.

4. Datta Prenati, urbanisation in India. 774-78, July, 2019.

5. Health Care and Hospital Management in India. 852-56, December, 2018.

How to cite: Mahmood S. Health care and hospital management in India. $J$ Manag Res Anal. 2020;7(3):136. 